\title{
Green synthesis of silver nanoparticles using (Eryngium Campestre) leaf extract
}

\author{
Maryam Khodaie, Nahid Ghasemi*, Majid Ramezani \\ Department of Chemistry, Arak Branch, Islamic Azad University, Arak, Iran
}

Received: 31 January 2019, Accepted: 9 May 2019, Published: 1 October 2019

\begin{abstract}
Biological synthesis of metallic nanoparticles is considered as a fast, eco-friendly, affordable and easily scalable technology. Also, the nanoparticles produced by plants are very stable. In this study, the focus is on the synthesis of silver nanoparticles using extract of eryngium campestre. The effective parameters such as concentration of silver nitrate, $\mathrm{pH}$, temperature and time, size and morphology of the nanoparticles were investigated and controlled by (UV-Vis) spectroscopy in the range of 300-500 $\mathrm{nm}$. Silver nanoparticles were synthesized under optimal conditions of $1 \mathrm{mM}$ silver nitrate, $\mathrm{pH}=5$, temperature $=50{ }^{\circ} \mathrm{C}$ and synthesis time of 100 minutes. Then, it was characterized by Fourier-transform infrared spectroscopy (FT-IR), X-ray powder diffraction (XRD), Scanning electron microscope (SEM), Energy dispersive X-ray (EDX) analysis.
\end{abstract}

Keywords: Silver nanoparticles; metallic nanoparticles; Eryngium campestre; green synthesis.

\section{Introduction}

Nowadays, nanotechnology has become one of the most promising and growing technologies in all sciences including physics, chemistry, biology, medicine, and materials science [1-3]. Metallic nanoparticles due to their unique properties and applications have attracted many attentions of the researchers all over the world. Due to the importance of metallic nanoparticles synthesis, the scientific community has taken extensive proceedings to develop appropriate techniques, new and safe methods for humans and environment for the production of nanoparticles [4,5]. Silver nanoparticles (AgNPs) which are one of the most important nanoparticles

*Corresponding author: Nahid Ghasemi

Tel: +98 (863) 4135421, Fax: +98 (863) 4135421

E-mail: n-ghasemi@iau-arak.ac.ir because of their antimicrobial and anticancer properties have very specific applications in infections and wounds treatment, medical and pharmaceutical cases, and surgical matters [6,7]. Typical chemical and physical synthesis methods have many disadvantages such as high cost, environmental and human hazards and the use of toxic chemical materials. These problems have attracted attention to the new and alternative routes. Phytochemicals reduction and synthesis of nanoparticles using plants and microorganisms as a new source for the synthesis and production of nanoparticles has been proven. This method has become a simple and efficient way because of its effective

Eurasian Chem. Commun., 2019, 441-450 
features like environmental compatibility, affordable, fast and safe method, without the need for high temperatures and specific conditions. Silver nanoparticles (AgNPs) which have been produced by this method can be used in various industries, including textile industry, creams and cosmetics [8,9], medical and surgical applications [10-12], because of its antibacterial properties [11]. There are secondary metabolites in the pure extract of plants, such as folic acid, flavoneides, alkanoids, and terpinetics, and etc. that play an important role in the plants defense system, and humans use them as medicine or spice, these metabolites are usually produced in certain plants and species. Reports have shown that there are different mechanisms for the synthesis of nanoparticles in different species [13]. The mechanism and elements involved in the synthesis of nanoparticles by plants have not been identified completely, but it has been suggested that the secondary metabolites play an important role in metallic salts reduction, as well as coating and stabilizing agent for silver nanoparticles [14]. Secondary metabolites are continuously used in the reactions required for the green synthesis of eco-friendly nanoparticles [15]. These reactions can be affected the shape and size of the nanoparticles $[16,17]$. In recent years, many plants have been investigated around the world to synthesize metallic nanoparticles, especially silver nanoparticles, which jasminoide (gardenia) [18], vitex negundo [19], thyme [20] and etc. are some examples of them. The eryngium campestre plant is one of the medicinal plants that, based on information from traditional medicine, have some therapeutic effects including; sedation, soothing the rheumatic diseases, relieving inflammation and pain [21]. Most of the compounds in eryngium campestre have different essential oils of folic acid, and its root contains tannin and sugar of sucrose. Also, the extract of eryngium campestre has high levels of phenol and flavonoids. As previously mentioned, polyphenolic phenol, such as flavonoids, can be used as a reducing agent in the synthesis of metallic nanoparticles by biological routes. Since the synthesis of silver nanoparticles has not been investigated by this plant, this study attempts to investigate this synthesis rout and effective parameters such as $\mathrm{pH}$, concentration of silver nitrate solution, temperature and time. Then, silver nanoparticles were synthesized under optimal conditions of all parameters, the obtained nanostructures were characterized by EDX, UV-VIS, XRD, SEM, and FTIR techniques.

\section{Experimental}

General

Fresh leaves of eryngium campestre were collected from around the city of Mazandaran in northern Iran. UV-Vis Perkin-Elmer spectrophotometer was used to study parameters and optimum conditions in the range of 300 to 500 $\mathrm{nm}$. IR spectra were taken by Bruker Alpha in the range of 500 to $4000 \mathrm{~cm}^{-1}$ with KBR. X-ray diffraction was recorded with a Philips PW 1730 Powder. The analysis was carried out at the current of $30 \mathrm{~mA}$ and $40 \mathrm{kV}$, step size $=0.02^{\circ}$ and step time $=1 \mathrm{~s}$ by monochromatized $\mathrm{Cu}$ radiation at $\lambda=1.5406 \AA$. The range of $2 \theta$ is from 10 to $80^{\circ}$. SEM was recorded with a thin layer of gold was coated for conductivity on the specimens and samples were analyzed at $20 \mathrm{kV}$ accelerator voltage. EDX was recorded with a TESCAN VEGA3. 


\section{Preparation of plant extract}

Eryngium campestre, which is a local herb, was collected from around the city of Mazandaran in northern Iran, and washed several times with deionized water and dried in shadow, and then it was prepared for extraction. For extraction, $20 \mathrm{gr}$ of dried leaves and $100 \mathrm{~mL}$ of deionized water were poured into an Erlenmeyer flask. Afterwards, it was boiled in water bath for 30 minutes and the extract was filtered after cooling using filter paper. The final extract was kept at $4{ }^{\circ} \mathrm{C}$ for further experiments.

\section{Synthesis of silver nanoparticles}

$10 \mathrm{~mL}$ of the eryngium campestre extract with $90 \mathrm{~mL}$ of $5 \mathrm{mM}$ silver nitrate solution was mixed. The color changing of the solution from yellow to brown indicates the synthesis of silver nanoparticles [22]. Finally, silver nanoparticles were characterized by XRD, FT-IR, SEM and EDX spectroscopy.

\section{Results and discussion}

After the synthesis of silver nanoparticles via eryngium campestre extract effective parameters on size and morphology of silver nanoparticles, including silver nitrate concentration, $\mathrm{pH}$, temperature and time were investigated. In order to determine the optimal conditions, UV-Vis spectroscopy was used in the range of 300-500 nm. Eryngium campestre collected from around the city of Mazandaran in northern Iran is shown in the Figure 1. In the first, the effect of silver nitrate concentration was investigated. Different concentrations of silver nitrate solution $(1,3,5$ and 10 $\mathrm{mM}$ ) were prepared. Then, $10 \mathrm{~mL}$ of the extract was added to $90 \mathrm{~mL}$ of each concentrations, After 30 minutes at room temperature $\left(25{ }^{\circ} \mathrm{C}\right)$, the maximum absorbance of each solution was recorded by UV-Vis spectrophotometer in the wavelength range of 300-500 $\mathrm{nm}$.

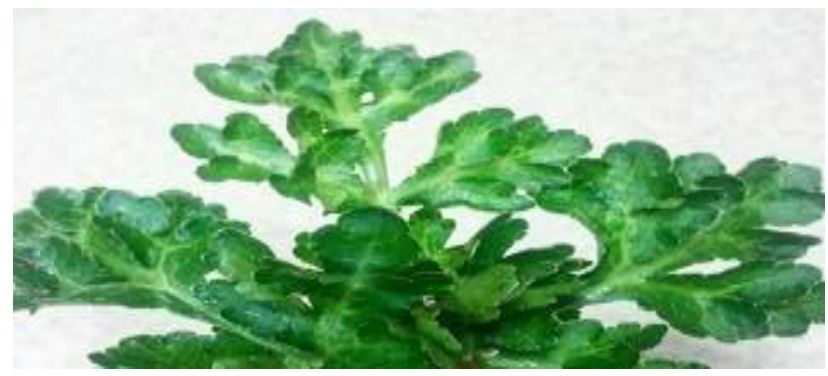

Figure 1. The fresh leaves Eryngium campestre

As shown in Figure 2, by increasing silver nitrate concentration, we observed that the absorption peak decreased, in fact, by decreasing surface plasm on particle size has been increased. It can be assumed that the amount of responsible metabolites for silver ions reduction in the extract is sufficiently available for concentration of $1 \mathrm{mM}$, and increasing silver ions concentration, reduces this access and larger nanoparticles have been synthesized and surface plasmon has been decreased. 


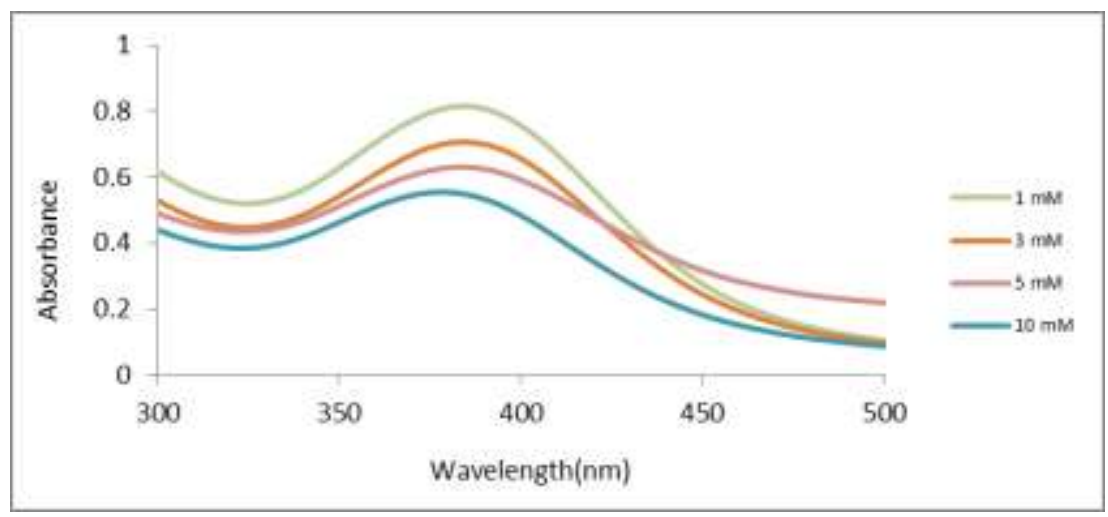

Figure 2. Effect of concentration silver on green synthesized AgNPs using (eryngium campestre) leaf extract $\left(\mathrm{pH}=3\right.$, temperature $=25^{\circ} \mathrm{C}$, time $=30 \mathrm{~min}$.)

$\mathrm{pH}$ is an important parameter in size and shape investigation of the nanoparticles. For this purpose, the optimum concentration of silver nitrate $(1 \mathrm{mM})$ was prepared and $90 \mathrm{~mL}$ of it and $10 \mathrm{~mL}$ of the extract were poured into 5 separate Erlenmeyer flask and $\mathrm{pH}$ of each Erlenmeyer was adjusted to $35,6,7$ and 9 by $0.1 \mathrm{~N} \mathrm{NaOH}$ and $\mathrm{HCl}$. After 30 minutes at room temperature $\left(25^{\circ} \mathrm{C}\right)$, the absorbance of each Erlenmeyer was recorded by UVVis spectrophotometer to determine the optimal $\mathrm{pH}$. According to the UV -Vis spectrophotometer results (Figure 3), it is clearly observed that with changing $\mathrm{pH}$ from 3 to 5 , the surface plasmon escalation is increased and peak has higher absorption, which represents the formation of smaller nanoparticles. This is probably due to the fact that the increase in $\mathrm{pH}$ will cause a change in the normal charge of the metabolites in the extract, which will have a positive effect on the adhesion and binding of silver ions, and the connection will be increased because the surface of metabolites become more negative and silver ions are positive. With $\mathrm{pH}$ increasing, the surface plasmon has decreased, which can be explained by the accumulation of nanoparticles, and for this reason, the surface plasmon has decreased and the particle size has become larger. According to the results the $\mathrm{pH}$ value of 5 was selected as the optimal $\mathrm{pH}$.

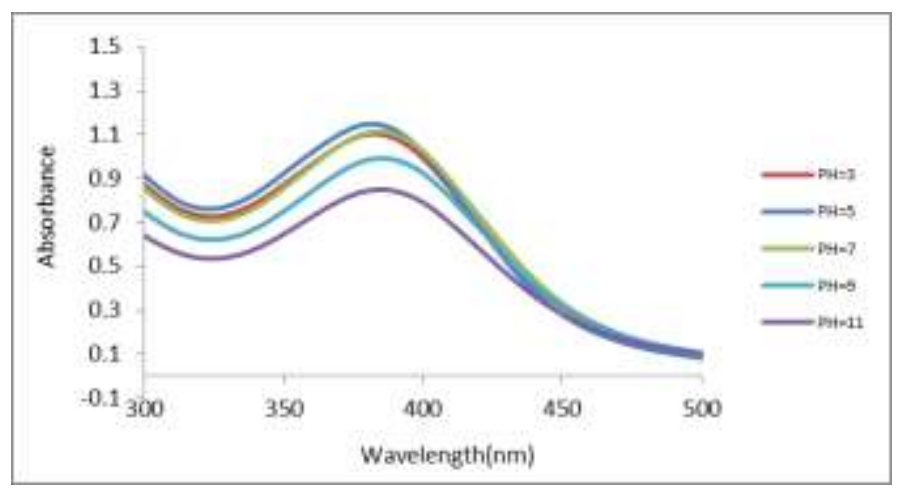

Figure 3. Effect of $\mathrm{pH}$ on green synthesized Ag NPs using (Eryngium campestre) leaf extract (concentration silver nitrate $=5 \mathrm{mM}, \mathrm{pH}=3$, temperature $=25^{\circ} \mathrm{C}$, time $=30$ minutes)

For investigation and achievement of nanoparticles with better size and morphology, temperature parameter has also been studied. For this purpose, 
Erlenmeyer flask containing $90 \mathrm{~mL}$ of silver nitrate solution with optimal concentration $(1 \mathrm{mM})$ and $10 \mathrm{~mL}$ of the extract with adjusted $\mathrm{pH}$ on optimum value were placed at different temperatures of $25,35,50,60^{\circ} \mathrm{C}$ for 30 minutes and their absorption was recorded by UV-Vis spectrophotometer. According to the results, the optimum temperature was selected. Due to the change in solution color from yellow to brown (Figure 4), it can be concluded that it is also possible to synthesize silver nanoparticles using Eryngium campestre plant at room temperature.

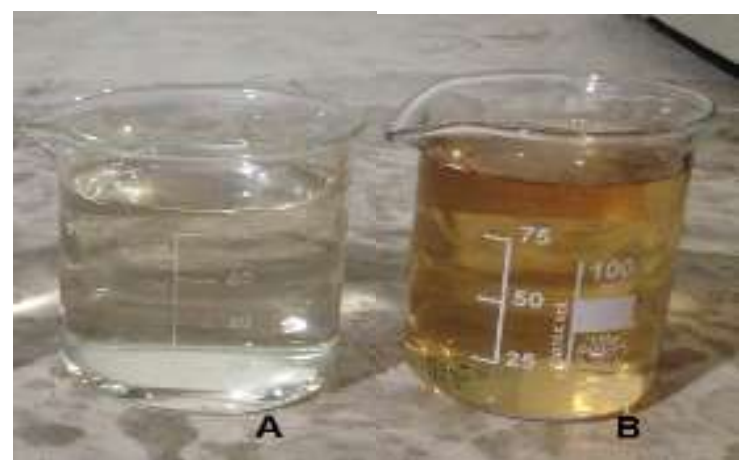

Figure 4. Green synthesized silver nanoparticles using (eryngium campestre) leaf extract a) leaf extract solution, b) change colour of the extract solution after reaction with $\mathrm{AgNO}_{3}$ and synthesized silver nanoparticles

As indicated, the synthesis of nanoparticles is carried out at ambient temperature and does not require high temperature, since the surface plasmons of metallic nanoparticles are strongly changed by temperature, in fact, increasing the temperature, increases reaction rate and enzymes activity and decreases the total reaction time, and can be synthesized nanoparticles which are more smaller and stable [23,24].

As shown in Figure 5, with increasing the temperature up to $50^{\circ} \mathrm{C}$, the absorption peak would be sharper and escalation of surface plasmon has been increased, which is a reason for particle size reducing. In this study, like in the previous one, with increasing the temperature up to $50^{\circ} \mathrm{C}$, the surface plasmon decreasing has been observed, which is probably due to the growth of crystals around the nucleus and accumulation of the particles, and the result is decreasing the absorption and increasing the particle size [25]. So it can be concluded that the temperature of $50{ }^{\circ} \mathrm{C}$ is the optimum temperature.

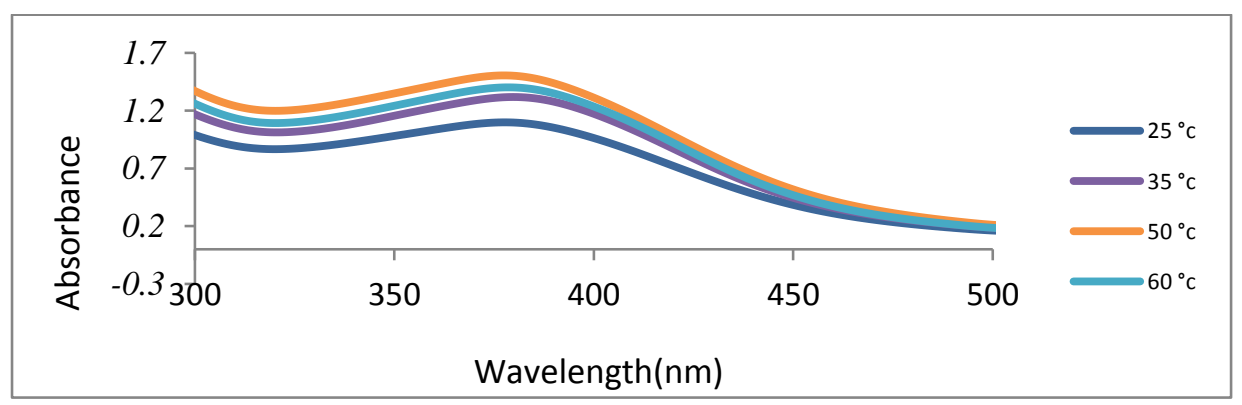

Figure 5. Effect of temperature on green synthesized AgNPs using (Eryngium campestre) leaf extract (concentration silver nitrate $=1 \mathrm{mM}, \mathrm{pH}=5$, time $=30$ minutes 
Time is also an important parameters for green synthesis of silver nanoparticles, because for the complete reaction and reduction of silver ions in the solution, there is a need for enough time to contact the reducing agents in the plant extract with silver ions. To evaluate this parameter, $90 \mathrm{~mL}$ of silver nitrate with optimum concentration (1 $\mathrm{mM}$ ) and $10 \mathrm{~mL}$ of extract were adjusted to optimum $\mathrm{pH}(5)$ at 5,15 , $30,40,50,60,80,100,120$ minutes at optimum temperature $\left(50{ }^{\circ} \mathrm{C}\right)$. After that the absorbance of the samples were recorded by UV-Vis spectrophotometer and according to the results, the optimum time for the synthesis was selected. As shown in Figure 6, absorption peak has been increased by increasing the time, which represents the preparation of smaller nanoparticles. According to the results, 100 minutes is the optimum time to complete the green synthesis of silver nanoparticles process.

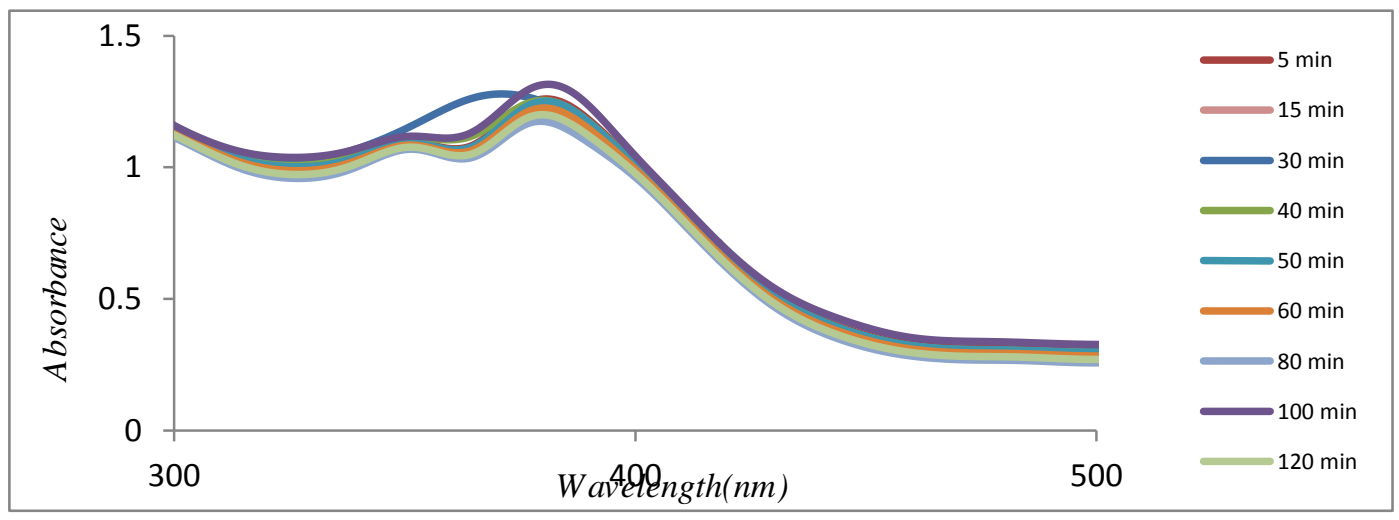

Figure 6. Effect of time on green synthesized AgNPs using (eryngium campestre) leaf extract (concentration silver nitrate $=1 \mathrm{mM}, \mathrm{pH}=5$, time $=30$ minutes)

As mentioned above, under the optimal conditions of all parameters, silver nanoparticles were characterized using FT-IR, XRD, SEM, EDX analysis.

FT-IR analysis was carried out from the as-prepared and dried sample to determine the factors and metabolites in plant, which are probably reducing agent for silver ions reduction. Figure 7 shows a peak at $3431.37 \mathrm{~cm}^{-1}$, which is related to the phenol and alcohols $(\mathrm{OH})$ groups, and peaks at $2923.12 \mathrm{~cm}^{-1}$ and $2857.55 \mathrm{~cm}^{-1}$ correspond to alkanes (C$\mathrm{H}$ stretch and carboxylic acid $(\mathrm{C}-\mathrm{OH})$ groups). Peaks at $1630 \mathrm{~cm}^{-1}$ and 1381 $\mathrm{cm}^{-1}$ belong to the Amin $(\mathrm{N}-\mathrm{H})$ and alkanes groups respectively, and 1263 $\mathrm{cm}^{-1}$, and $1066 \mathrm{~cm}^{-1}$ and $466 \mathrm{~cm}^{-1}$ also indicates alkyl halides [26]. Hydroxyl groups, phenolic compounds and existence amines in the pure extract of plants are very strong reducing agents responsible for reducing $\mathrm{Ag}^{+}$ions to $\mathrm{Ag}{ }^{0}$. These agents have a strong tendency to connect and reduce silver ions and cover nanoparticles and provide a protective layer that prevent accumulation, which will stabilize them in the solution. 

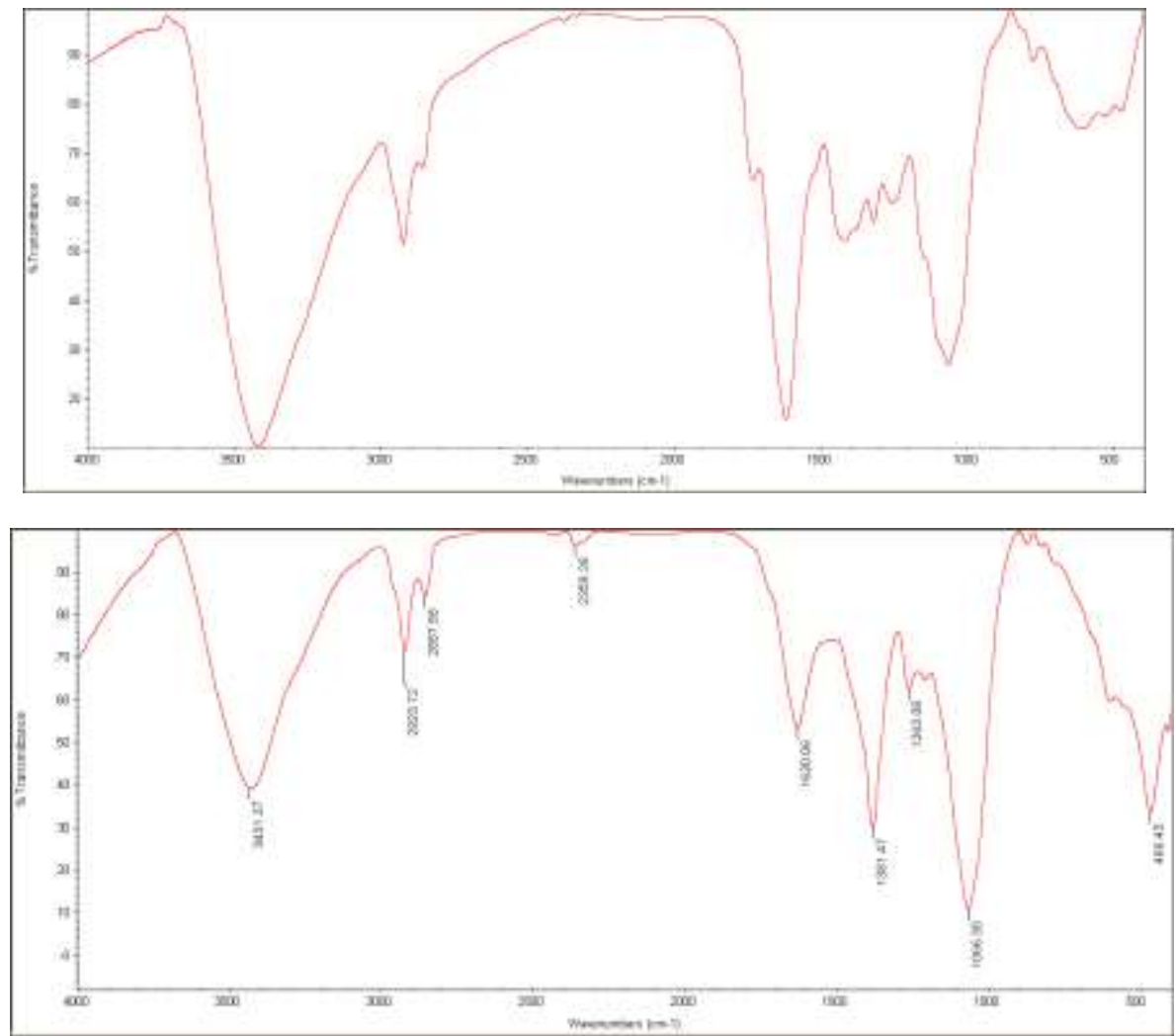

Figure 7. a) FT-IR analysis of (Eryngium campestre. b) FT-IR analysis of synthesized AgNPs using (eryngium campestre) leaf extract (concentration silver nitrate $=1 \mathrm{mM}, \mathrm{pH}=5$, temperature $=50^{\circ} \mathrm{C}$, time $=100$ minutes)

The X-ray diffraction pattern of silver nanoparticles is shown in Figure 8 , which indicates the crystallinity of these nanoparticles. $X$ pert high score software was used to analyze the phase and that the silver nanocrystals production were approved according to the diffraction spectrum with the standard issue number of 04-0783. The angle of diffraction is from 10 to 80 , that the sharp peaks of this pattern at $37.914,44.159,64.372,77.349$ are related to the Khl (111), (200), (220), (311) plates. According to these results, the structure of nanoparticles is cubic. The average size of crystalline silver nanoparticles was calculated using Debye-Scherrer equation [27] about 19 nm (Table 1).

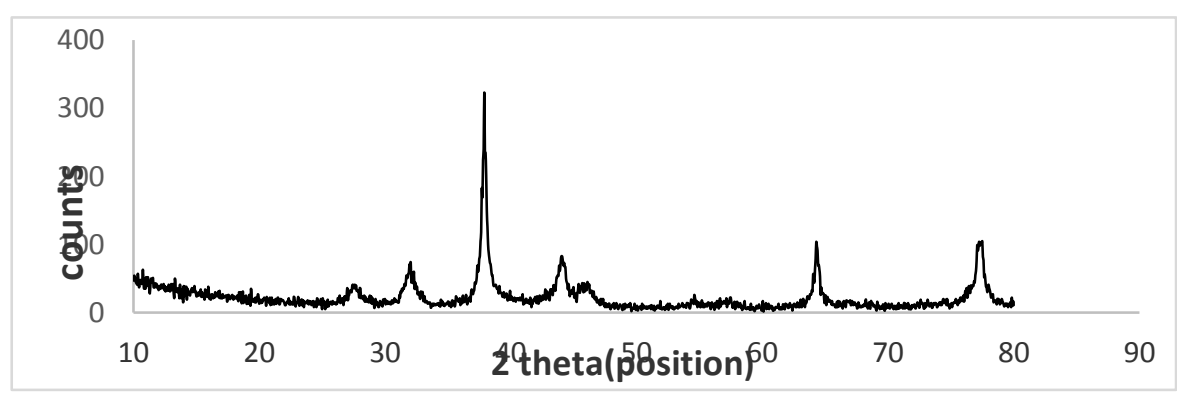

Figure 8. XRD pattern of synthesized AgNPs using (Eryngium campestre) leaf extract (concentration copper nitrate $=1 \mathrm{mM}, \mathrm{pH}=5$, Temperature $=50^{\circ} \mathrm{C}$, time $=100$ minutes $)$ 
Table 1. Powder X-ray diffraction data for AgNPs

\begin{tabular}{ccccc}
\hline No. & Position [ ${ }^{\circ}$ 2Theta] & ${\text { FWHM [ }{ }^{\circ} \text { Theta] }}$ & h k l & d-spacing \\
\hline $\mathbf{1}$ & 37.9151 & 0.1968 & 111 & 2.37308 \\
$\mathbf{2}$ & 64.3729 & 0.2952 & 220 & 1.44729 \\
$\mathbf{3}$ & 77.3439 & 0.6 & 311 & 1.23275 \\
\hline
\end{tabular}

\section{$\mathrm{D}=\mathrm{K} \lambda / \beta \cos \theta$}

$\mathrm{D}=$ is the mean size of the ordered (crystalline) domains

$\mathrm{B}=$ is the line broadening at half the maximum intensity

$\theta=$ is the Bragg angle

$\lambda=$ is the $\mathrm{X}$-ray wavelength

The results of EDX analysis (Figure 9) of synthesized nanoparticles using Eryngium campestre plant confirm the presence of silver with the highest percentage. Also, analysis showed the presence of carbon, oxygen, and chlorine, which can be related to the metabolites that cause silver ions reduction in plant extract (Table 2).

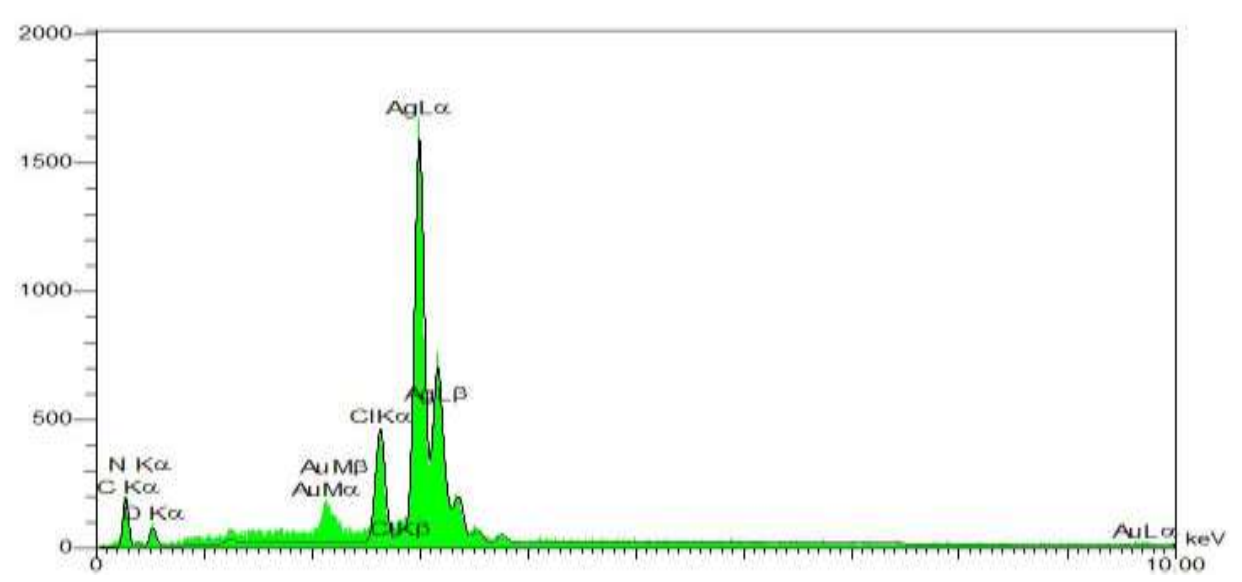

Figure 9. EDX analysis of synthesized AgNPs using (eryngium campestre) leaf extract (concentration copper nitrate $=1 \mathrm{mM}, \mathrm{pH}=5$, Temperature $=50^{\circ} \mathrm{C}$, time $=100$ minutes)

Table 2. Information EDX data for AgNPs

\begin{tabular}{ccc}
\hline Element & W\% & $\mathbf{A \%}$ \\
\hline $\mathrm{C}$ & 3.26 & 19.87 \\
$\mathrm{~N}$ & 0.47 & 2.45 \\
$\mathrm{O}$ & 1.49 & 6.81 \\
$\mathrm{Cl}$ & 4.73 & 9.76 \\
$\mathrm{Ag}$ & 90.05 & 61.1 \\
total & 100 & \\
\hline
\end{tabular}

Morphology and size of the magnitudes, the average size of nanoparticles are shown in SEM nanoparticles are between 25-30 images (Figure 9). In 500 nanoscale nanometers. 


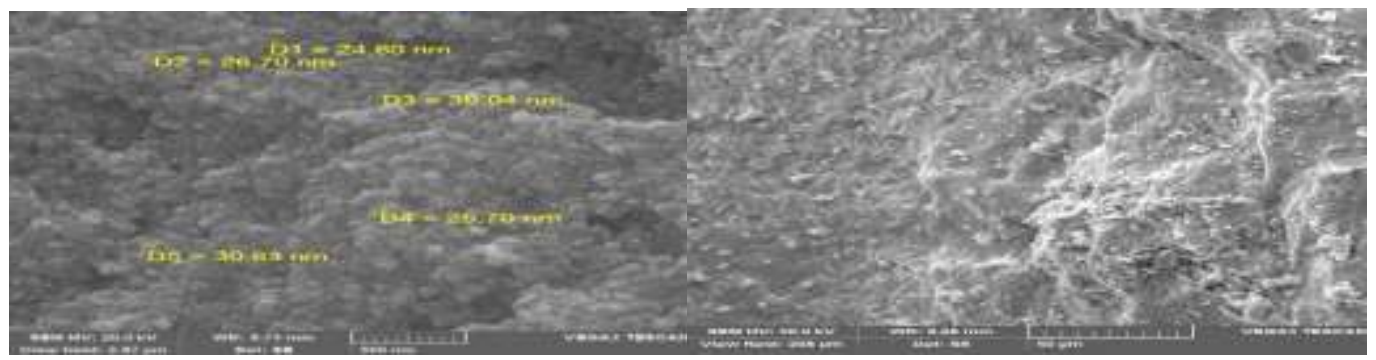

Figure 10. SEM Micrograph of synthesized AgNPs using (eryngium campestre) leaf extract (concentration copper nitrate $=1 \mathrm{mM}, \mathrm{pH}=5$, Temperature $=50^{\circ} \mathrm{C}$, time $=100$ minutes)

Mechanisms and reactions involved in green synthesis of metallic nanoparticles using plants are not clear yet [28], but suggestions have made it clear that metabolites in plants, such as flavonoids, alkaloids, etc. play an important role in metallic salts reduction, and also have a big role in nanoparticles stabilization by creating a protective layer that prevents accumulation. There are three main steps in the synthesis of nanoparticles using plants. In the first step, which is the activation step, metallic ions are reduced by metabolites and reducing agents of the plants. For example, Ag+ ions are converted to $\mathrm{Ag}^{0}$ and then started to nucleate. In the second step, the particle growth step, particles accumulate with adjacent particles and create a stable state thermodynamically. The third step is the final formation step, in which the type of the extract and metabolites play an important role in the formation and stabilization of nanoparticles [29].

\section{Conclusion}

In sum, we investigated the synthesis of silver nanoparticles using eryngium campestre plant with therapeutic and antioxidant properties. We studied four parameters, including silver nitrate concentrations, $\mathrm{pH}$, temperature and time to improve morphology and control the particle size. UV-Vis analysis was used for studying and optimizing each parameter. According to the results, silver nitrate concentration $=1 \mathrm{mM}, \mathrm{pH}=5$, temperature $=50{ }^{\circ} \mathrm{C}$ and optimal time of 100 minutes were selected as optimum parameters for this synthesis. Sediment was achieved from solution under these conditions, then FTIR, XRD, SEM, and EDX were used to analyze it. XRD results indicate the crystallinity of silver nanoparticles. FTIR results indicate the presence of carboxylic, amine and phenols groups, which confirmed probability of the existence of flavonoids compounds for silver ions reduction. Morphology of nanoparticles is shown in SEM images, and the particle size can be estimated within the range of 25-30 nm. According to EDX results, the highest percentage of element is for silver, which confirms the synthesis of silver nanoparticles.

\section{Acknowledgements}

The authors are grateful to the Arak Branch, Islamic Azad University forfinancial supports.

\section{References}

[1] M.A. Albrecht, C. W. Evans, C. L. Raston, Green Chem., 2006, 8, 417432.

[2] M. Rai, A. Yadav, A. Gade, C. Rev, Biotechnol., 2008, 28, 277-284.

[3] J. Huang, C. Chen, N. He, J. Hong, Y. Lu, L. Qingbiao, D. Sun, Y. Su, X. Yang, H. Wang, Y. Wang, W. Shao, N. $\mathrm{He}$, J. Hong, C. Chen. Nanotechnology., 2007, 18, 105-106. 
[4] Z. Liu, D.G. Bucknall, M.G. Allen, Nanotechnology., 2011, 22, 225-302.

[5] P. Mohanpuria, N.K. Rana, S.K. Yadav, J. Nanoparticle. Res., 2008, 10, 507-517.

[6] C. Dipankar, S. Murugan, Colloids. Surf. B: Biointerfaces., 2012, 98, 112 119.

[7] R.O. Becker, J.A. Spadaro, J. Bone. Joint. Surg., 1978, 60, 871-881.

[8] F. Martinez-Gutierrez, P.L. Olive, A. Banuelos, E. Orrantia, N. Nino, E.M. Sanchez, Nanomedicine, 2010, 6, 681-688.

[9] S. Kokura, O. Handa, T. Takagi, T. Ishikawa, Y. Naito, T. Yoshikawa, Nanomedicine., 2010, 6, 570-574.

[10] D.S. Goodsell, Bionanotechnology: lessons from nature. Wiley, Hoboken, 2004.

[11] R. Shaikh, I. Zainuddin Syed, Payoshni Bhende. Asian Journal of Green Chemistry., 2019, 3, 70-81.

[12] K. Yokohama, D.R. Welchons, Nanotechnology., 2007, 18, 105101105107.

[13] N. Vigneshwaran, A.A. Kathe, P.V. Varadarajan, R.P. Nachane, R.J. Balasubramanya, J. Nanosci. Nanotechnol., 2007, 7, 1893-1897.

[14] U. Suriyakalaa, J.J. Antony, S. Suganya, D. Siva, R. Sukirtha, S. Kamalakkannan, T. Pichiah, S. Achiraman, Coll. Surf. B., 2013, 102, 189-194.

[15] D. Elumalai, M. Sathiyaraj, E. Vimalkumar, P.K. Kaleena, M. Hemavathi, P. Venkatesh. Asian Journal of Green Chemistry, 2019, 3, 103-124.

[16] S. Dubey, M. Lahtinen, M. Särkkä, H. Sillanpää, Colloid. Surf. B., 2010, 80, 26-33.
[17] S.P. Chandran, M. Chaudhary, R. Pasricha, A. Ahmad, M. Sastry. Biotechnol. Prog., 2006, 22, 577-583.

[18] F. LU, Y. Gao, J. Huang, D. Sun, Q. Li, Chin. Chem. Eng., 2014, 22, 706-712.

[19] A. Shukla, B.A. Makwana, Am. J. Nanoscience Nanotechnol., 2014, 2, 8492.

[20] A. Jafari, L. Pourakbar, K. Farhadi, L. Mohamadgolizad, Y. Goosta, Turk. J. Biol., 2015, 39, 556561.

[21] S. Cone, A.E. Pârvu, M.A. Taulescu, L. Vlase, Digest. J. Nanomaterials Biostruc., 2015, 10, 693 -704 .

[22] D. Sreemanti, D. Jayeeta, S. Asmita, B.C. Soumya Sundar, D. Durba, R. Anisur, B. Khuda, Colloids Surf. B: Biointerface., 2013, 101, 325 336.

[23] J. ha, A.K. Prasad, J. Green Nanotech. Phy: Chem., 2010, 1, 110117.

[24] S.P. Dubey, M. Lahtinen, M. Sillanpaa, Process Biochem, 2010, 45, 1065-1071.

[25] J.Y. Song, B.S. Kim, Bioprocess Biosyst. Eng., 2009, 32, 79-84.

[26] S. Alizadeh, T. Madrakian, M. Bahram, Adv. J. Chem. A., 2019, 2, 5772.

[27] E. Arshadi, S. Sedaghat, O. Moradi, Asian Journal of Green Chemistry., 2018, 2, 41-50.

[28] N. Khatoon, J.A. Mazumder, M. Sardar, J. Nanosciences: Current Res., 2017, 2, 107-114.

[29] S. Si, T.K. Mandal. Chem. Eur. J., 2007, 13, 3160- 3168.

How to cite this manuscript: Maryam Khodaie, Nahid Ghasemi, Majid Ramezani. "Green synthesis of silver nanoparticles using (Eryngium Campestre) leaf extract". Eurasian Chemical Communications, 2019, 441-450. 